
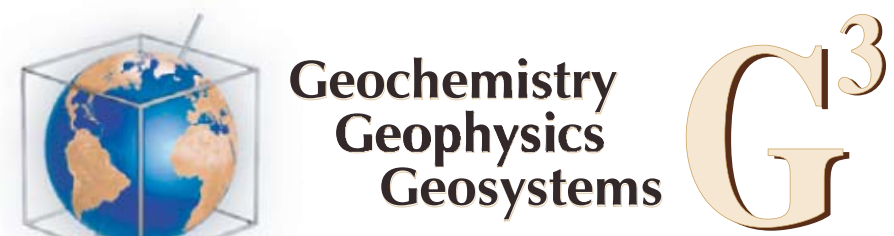

Published by AGU and the Geochemical Society

\title{
Online preconcentration ICP-MS analysis of rare earth elements in seawater
}

\section{Ed C. Hathorne}

Helmboltz Centre for Ocean Research Kiel (GEOMAR), D-24148 Kiel, Germany

(ehathorne@geomar.de)

\section{Brian Haley}

College of Ocean and Atmospheric Sciences, Oregon State University, Corvallis, Oregon 97331, USA

\author{
Torben Stichel \\ Helmboltz Centre for Ocean Research Kiel (GEOMAR), D-24148 Kiel, Germany \\ Now at School of Ocean and Earth Science and Technology, University of Hawai i at Mãnoa, \\ Honolulu, Hawaii 96822, USA
}

\author{
Patricia Grasse, Moritz Zieringer, and Martin Frank \\ Helmboltz Centre for Ocean Research Kiel (GEOMAR), D-24148 Kiel, Germany
}

[1] The rare earth elements (REEs) with their systematically varying properties are powerful tracers of continental inputs, particle scavenging intensity and the oxidation state of seawater. However, their generally low $(\sim \mathrm{pmol} / \mathrm{kg})$ concentrations in seawater and fractionation potential during chemical treatment makes them difficult to measure. Here we report a technique using an automated preconcentration system, which efficiently separates seawater matrix elements and elutes the preconcentrated sample directly into the spray chamber of an ICP-MS instrument. The commercially available "seaFAST" system (Elemental Scientific Inc.) makes use of a resin with ethylenediaminetriacetic acid and iminodiacetic acid functional groups to preconcentrate REEs and other metals while anions and alkali and alkaline earth cations are washed out. Repeated measurements of seawater from $2000 \mathrm{~m}$ water depth in the Southern Ocean allows the external precision $(2 \sigma)$ of the technique to be estimated at $<23 \%$ for all REEs and $<15 \%$ for most. Comparison of $\mathrm{Nd}$ concentrations with isotope dilution measurements for 69 samples demonstrates that the two techniques generally agree within $15 \%$. Accuracy was found to be good for all REEs by using a five point standard addition analysis of one sample and comparing measurements of mine water reference materials diluted with a $\mathrm{NaCl}$ matrix with recommended values in the literature. This makes the online preconcentration ICP-MS technique advantageous for the minimal sample preparation required and the relatively small sample volume consumed $(7 \mathrm{~mL})$ thus enabling large data sets for the REEs in seawater to be rapidly acquired.

Components: 6400 words, 6 figures, 3 tables.

Keywords: ICP-MS; rare earth elements.

Index Terms: 1050 Geochemistry: Marine geochemistry (4835, 4845, 4850); 4803 Oceanography: Biological and Chemical: Analytical chemistry; 4875 Oceanography: Biological and Chemical: Trace elements (0489). 
Received 7 October 2011; Revised 19 December 2011; Accepted 22 December 2011; Published 31 January 2012.

Hathorne, E. C., B. Haley, T. Stichel, P. Grasse, M. Zieringer, and M. Frank (2012), Online preconcentration ICP-MS analysis of rare earth elements in seawater, Geochem. Geophys. Geosyst., 13, Q01020, doi:10.1029/2011GC003907.

\section{Introduction}

[2] The rare earth elements (REEs) are chemically similar but their ionic radii decrease with increasing atomic number resulting in systematic differences in their speciation in seawater [e.g., Cantrell and Byrne, 1987; Elderfield, 1988; Quinn et al., 2006]. This and the special case of cerium III oxidation to the insoluble cerium IV state combine to make the REEs useful tracers of continental inputs, particle scavenging, and the oxidation state of seawater [e.g., Elderfield and Greaves, 1982; De Baar et al., 1985; German and Elderfield, 1990a; Sholkovitz and Schneider, 1991; Bertram and Elderfield, 1993; Sholkovitz et al., 1994]. However, the generally low $(\sim \mathrm{pmol} / \mathrm{kg})$ concentrations of REEs and fractionation potential during chemical treatment make them difficult to measure in seawater. This has resulted in a relatively sparse coverage of reliable data for the REE distribution in the oceans [e.g., Piepgras and Jacobsen, 1992]. Nevertheless, the general pattern of the REE distribution in the water column is known and some studies have documented distinctions in the normalized REE patterns for particular regions and water masses [e.g., Piepgras and Jacobsen, 1992; Bertram and Elderfield, 1993; Amakawa et al., 2000], while others have highlighted the usefulness of heavy REE ratios for tracing water masses [e.g., Zhang and Nozaki, 1996]. Additionally, anthropogenic pollution has been identified using the REE patterns in seawater [e.g., Censi et al., 2004] and rivers [e.g., Bau and Dulski, 1996; Kulaksız and Bau, 2011]. Despite an understanding of the broad processes controlling the REE abundance in the water column [e.g., Cantrell and Byrne, 1987; Elderfield, 1988; Quinn et al., 2006], the widespread application of the REEs in chemical oceanography and paleoceanography is currently hindered by a lack of data coverage, both spatially and temporally [e.g., German and Elderfield, 1990b; Bertram and Elderfield, 1993]. Therefore a technique enabling REE concentrations in seawater to be measured more easily could open new avenues of research.

[3] Most previous techniques to measure the REEs in seawater have required sample volumes of $\sim 1 \mathrm{~L}$ and time consuming chemical preparation techniques. The most precise way to measure REE concentrations in seawater samples is by isotope dilution but this is very time consuming, requiring a calibrated multi-element spike, and the concentrations of the mono-isotopic lanthanides cannot be determined [e.g., Greaves et al., 1989]. Shabani et al. [1990] describe a solvent extraction and back extraction technique that removes matrix elements and preconcentrates the REEs 200 fold for measurement by ICP-MS. The solvent extraction technique is relatively rapid (30 min per sample), produces precise and accurate results and has been extensively used to generate seawater REE data [e.g., Zhang and Nozaki, 1996; Alibo and Nozaki, 1999; Nozaki et al., 1999; Amakawa et al., 2000; Nozaki and Alibo, 2003], but the extractions are conducted manually. The solvent extraction technique was later modified to also obtain reliable results for lower ionic strength samples [Aggarwal et al., 1996], though unfortunately, an automated online solvent extraction procedure was not sensitive enough to measure the REEs in natural seawater samples [Shabani and Masuda, 1991].

[4] Solid phase techniques have been developed to pre-concentrate the REEs in seawater samples and remove matrix elements prior to ICP-MS analysis and include co-precipitation [e.g., Shaw et al., 2003; Bayon et al., 2011; Freslon et al., 2011] and using columns packed with chelating compounds [e.g., Möller et al., 1992; Hall et al., 1995; Zhu et al., 2006; Rahmi et al., 2007; Kim et al., 2010]. Ion chromatography systems have been coupled with ICP-MS instruments to preconcentrate the REEs in natural waters for online analysis [Douville et al., 2002; Haley and Klinkhammer, 2003]. Measurement of the REEs in mainly coastal seawater samples has been achieved by online preconcentration (OP) coupled with ICP-MS using chelating columns with 8HQ [Halicz et al., 1996; Kajiya et al., 2004], alkyl phosphinic acid [Fu et al., 2007], IDA functional groups [Willie and Sturgeon, 2001; Hirata et al., 2002] and with both IDA and ED3A functional groups [Zhu et al., 2009]. Despite the promise of these OP-ICP-MS techniques to rapidly analyze seawater REEs with only a few $\mathrm{mL}$ of sample consumption the results have been mixed with variable recoveries across the REEs [Hirata et al., 2002; Kajiya et al., 2004]. It is difficult to judge most of these techniques from analyses of the NASS 
seawater reference material that is not certified for the REEs and appears to be contaminated with Sm [Lawrence and Kamber, 2007]. Although new data for the NASS-5 [Freslon et al., 2011] support the accuracy of some of the OP-ICP-MS techniques none have been widely applied to real open ocean seawater samples.

[5] Here we report a fully automated OP-ICP-MS technique for the analysis of REEs in seawater utilizing a commercially available system. We demonstrate the good precision and accuracy of the technique and apply it to open ocean seawater samples. This OP-ICP-MS technique takes about 15 min per sample and is advantageous because of the minimal sample preparation and volumes required ( $7 \mathrm{~mL}$ per analysis) and that it can run continuously for many days.

\section{Methods}

\subsection{Online Preconcentration (OP)}

[6] The commercially available seaFAST system (Elemental Scientific Inc., Nebraska, USA) uses a resin with ethylenediaminetriacetic acid and iminodiacetic acid functional groups (part number CF$\mathrm{N}-0200$ ) to preconcentrate REEs and other metals while anions and alkali and alkaline earth cations are washed out. The system consists of an auto-sampler and two inert 6-port valves (for schematic see http:// www.icpms.com/pdf/seaFAST_REE_ICPMS_Element2. pdf). Reagents are pumped using a peristaltic pump (Perimax, SPETEC AG, Erding, Germany) operating at $19 \mathrm{rpm}$ and using standard PVC pump tubing. The FAST auto-sampler uses a vacuum to fill a PTFE sample loop with $4.2 \mathrm{~mL}$ of filtered and acidified ( $\mathrm{pH} \sim 2$ ) seawater. To ensure that the entire sample loop is filled a larger sample volume $(\sim 7 \mathrm{~mL})$ is consumed. The sample in the loop is pushed onto the resin column (resin volume $200 \mu \mathrm{L}$ ) by a continuous flow ( $\sim 1 \mathrm{~mL} / \mathrm{min}$ ) of $18.2 \mathrm{M} \Omega \mathrm{cm}$ water (Milli-Q). The column is maintained at $\mathrm{pH} \sim 6$ by a continuous flow $(\sim 0.5 \mathrm{~mL} / \mathrm{min})$ of ammonium acetate prepared with trace metal purity acetic acid at $1.2 \mathrm{M}$ and ammonia solution at $1.1 \mathrm{M}$, diluted with Milli-Q water. The ammonium acetate buffer solution and water (sample) mix between the sample loop and the column. The sample is loaded and the column flushed for $10 \mathrm{~min}$ to remove alkali and alkaline earth elements. Meanwhile, a continuous flow $(\sim 0.3 \mathrm{~mL} /$ min) of trace metal purity $1.5 \mathrm{M} \mathrm{HNO}_{3}$ with $0.4 \%$ acetic acid (elution acid as recommended by the manufacturer) is pumped through the valve bypassing the column and is aspirated with a micro-Flow
PFA nebulizer into the spray chamber of the ICPMS. Once the matrix has been sufficiently washed out, the valve is switched so that the flow of $\mathrm{HNO}_{3}$ passes over the column in the reversed direction from the column loading and the REEs and other preconcentrated metals are eluted into the ICP-MS for measurement. The eluting $\mathrm{HNO}_{3}$ passes over the column for $\sim 5$ min stripping it of metals before the valve switches back to condition the column for the next analysis.

\subsection{OP-ICP-MS}

[7] At the beginning of each analysis session the Agilent 7500 ICP-MS was optimized for sensitivity, while keeping $\mathrm{CeO}$ and $\mathrm{Ce}^{2+}$ formation to $\sim 1 \%$, by pumping a $1 \mathrm{ppb}$ tune solution $(\mathrm{Li}, \mathrm{Y}, \mathrm{Ce}$, Tl) through the $\mathrm{HNO}_{3}$ line bypassing the column. Typical operating conditions and the isotopes monitored are summarized in Table 1. Tests were made with ${ }^{147} \mathrm{Sm},{ }^{149} \mathrm{Sm},{ }^{172} \mathrm{Yb}$, and ${ }^{174} \mathrm{Yb}$, but no systematic difference was observed between the two isotopes for either element. Indium (In) was added to all samples and standards to have a concentration of $100 \mathrm{ppt}$, providing a means to check the loop filled and the elution proceeded properly. Indium correction was only used in a few instances where the correction was $>5 \%$. Time resolved (TR) analysis was performed to establish the timing of the elution peak for each column and batch of reagents (Figure 1). Calibration standards were diluted from a mixed REE stock solution in $2 \%$ $\mathrm{HNO}_{3}$ with high purity $\mathrm{NaCl}$ (MERK Suprapur) to achieve a salinity of $35 \mathrm{~g} / \mathrm{L}$ and were passed through the column and analyzed in the same way as samples. Linear calibration curves were obtained for all elements over the concentration range of interest $(0.1$ to $10 \mathrm{ppt})$. Column yields were estimated by pumping standard solutions diluted in elution acid (1.5 $\mathrm{M} \mathrm{HNO}_{3}$ with $0.4 \%$ acetic acid) through the $\mathrm{HNO}_{3}$ line bypassing the column for TR analysis.

\section{Results and Discussion}

\subsection{Blanks and Detection Limits}

[8] Blank solutions of $2 \% \mathrm{HNO}_{3}$ and $\mathrm{NaCl}$ matrix in $2 \% \mathrm{HNO}_{3}$, both with $\mathrm{In}$ at $100 \mathrm{ppt}$, were run through the column and analyzed frequently. Data from a typical analysis session are summarized in Table 2 and indicate the low background levels producing sub ppt detection limits for most REEs. Generally the signal-to-noise ratio for surface samples with the lowest concentration is $>10$ 
Table 1. Instrument (Agilent 7500) Operating Conditions

\begin{tabular}{ll}
\hline \multicolumn{1}{c}{ Instrument } & \multicolumn{1}{c}{ Operating Condition } \\
\hline RF power & $1500 \mathrm{~W}$ \\
Coolant Ar flow & $15 \mathrm{~L} / \mathrm{min}$ \\
Make-up Ar flow & $0.23 \mathrm{~L} / \mathrm{min}$ \\
Carrier Ar flow & $0.90 \mathrm{~L} / \mathrm{min}$ \\
Nebulizer & PFA micro-flow pumped at $0.3 \mathrm{~mL} / \mathrm{min}$ \\
Spray chamber & Quartz Scott type \\
Extraction lens configuration & CE type \\
Reaction cell & No gas mode \\
Detector mode & Pulse counting $(\mathrm{Na}$ analogue $)$ \\
Points per mass & 11 \\
Dwell time & $0.1 \mathrm{~s}$ \\
Sweep time & $2.12 \mathrm{~s}$ \\
Isotopes monitored & ${ }^{23} \mathrm{Na},{ }^{89} \mathrm{Y},{ }^{115} \mathrm{In},{ }^{137} \mathrm{Ba},{ }^{139} \mathrm{La},{ }^{140} \mathrm{Ce},{ }^{141} \mathrm{Pr}$, \\
& ${ }^{146} \mathrm{Nd},{ }^{147} \mathrm{Sm},{ }^{149} \mathrm{Sm},{ }^{153} \mathrm{Eu},{ }^{157} \mathrm{Gd},{ }^{159} \mathrm{~Tb}$, \\
& ${ }^{163} \mathrm{Dy},{ }^{165} \mathrm{Ho},{ }^{166} \mathrm{Er},{ }^{169} \mathrm{Tm},{ }^{172} \mathrm{Yb},{ }^{174} \mathrm{Yb}$, \\
\hline
\end{tabular}

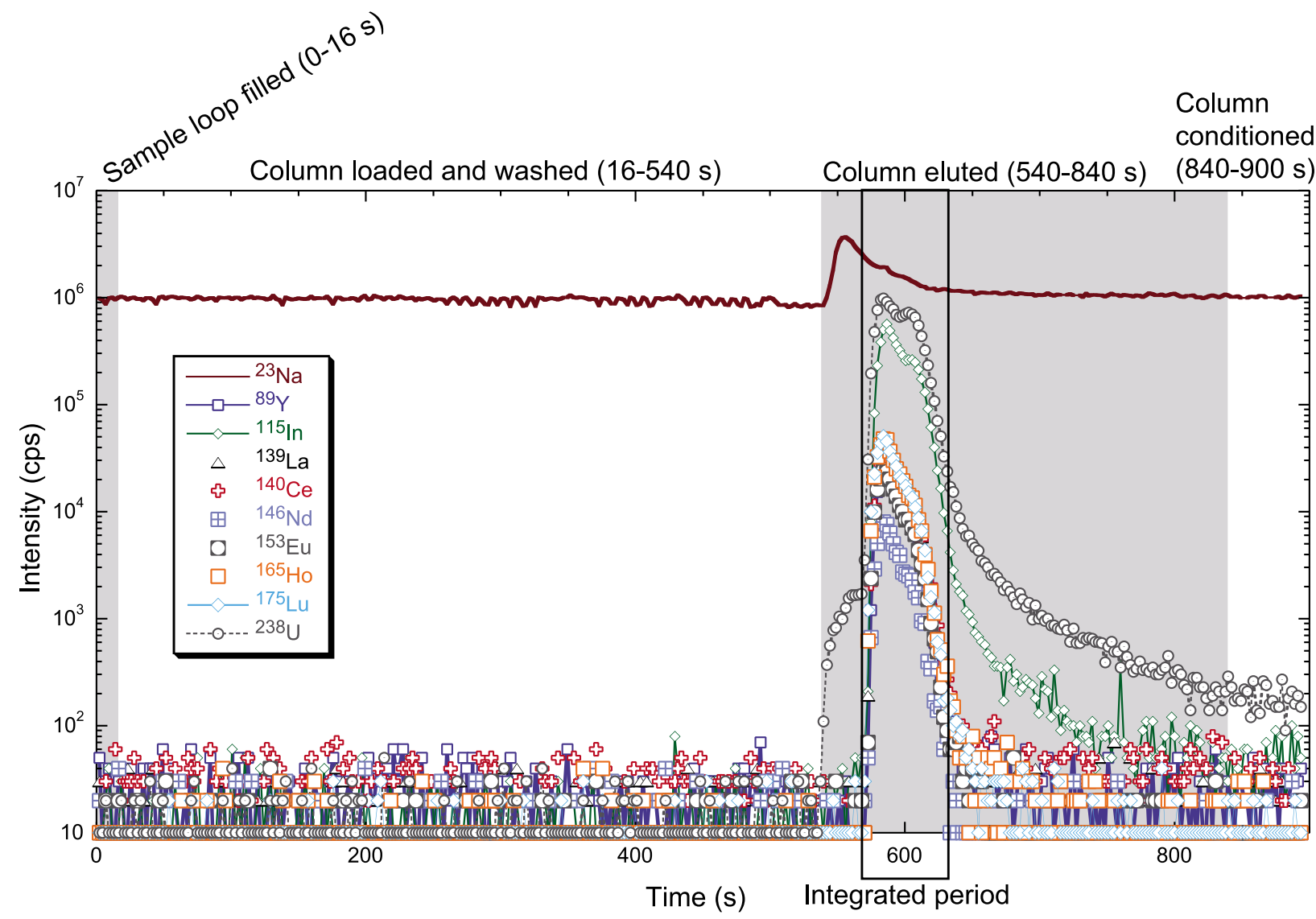

Figure 1. Time Resolved Analysis (TRA) of the online preconcentration and elution of a 5 ppt REE standard solution diluted with $\mathrm{NaCl}$ matrix. During normal analyses data is only collected during the integrated period (indicated by the framed rectangle). Note the timing of the indium and uranium elution is slightly different to that of the REE. Uranium was monitored as a natural internal standard for open ocean samples. 
Table 2. Typical Blanks, Detection Limits and Column Yields ${ }^{\mathrm{a}}$

\begin{tabular}{lccccccccccccccc}
\hline & $\mathrm{Y}$ & $\mathrm{La}$ & $\mathrm{Ce}$ & $\mathrm{Pr}$ & $\mathrm{Nd}$ & $\mathrm{Sm}$ & $\mathrm{Eu}$ & $\mathrm{Gd}$ & $\mathrm{Tb}$ & $\mathrm{Dy}$ & $\mathrm{Ho}$ & $\mathrm{Er}$ & $\mathrm{Tm}$ & $\mathrm{Yb}$ & $\mathrm{Lu}$ \\
\hline 2\% $\mathrm{HNO}_{3}$ average blank cps (n = 5) & 117 & 143 & 99 & 14 & 13 & 9 & 7 & 6 & 4 & 7 & 12 & 7 & 12 & 8 & 11 \\
$2 \% \mathrm{HNO}_{3}$ detection limit (ppq) & 275 & 302 & 142 & 12 & 36 & 10 & 9 & 17 & 2 & 15 & 10 & 4 & 9 & 9 & 7 \\
$\mathrm{NaCl}$ solution average blank cps (n $=5)$ & 238 & 109 & 180 & 24 & 27 & 8 & 7 & 338 & 11 & 8 & 10 & 12 & 7 & 13 & 9 \\
$\mathrm{NaCl}$ solution detection limit (ppq) & 67 & 15 & 39 & 7 & 37 & 23 & 5 & 105 & 5 & 15 & 1 & 9 & 1 & 11 & 3 \\
Empty seawater av. blank cps (n = 4) & 147 & 101 & 85 & 21 & 20 & 8 & 6 & 9 & 9 & 10 & 11 & 10 & 9 & 9 & 7 \\
Empty seawater detection limit (ppq) & 25 & 36 & 12 & 6 & 19 & 31 & 4 & 17 & 1 & 5 & 2 & 9 & 4 & 11 & 3 \\
Average column yield \% (n = 2) & 102 & 102 & 98 & 99 & 96 & 100 & 97 & 94 & 99 & 99 & 99 & 100 & 98 & 97 & 100 \\
Standard deviation of yields \% & 3 & 3 & 2 & 2 & 1 & 4 & 1 & 1 & 1 & 2 & 1 & 3 & 1 & 1 & 1 \\
\hline
\end{tabular}

${ }^{\mathrm{a}}$ Units are in counts per second (cps), parts per quadrillion or $10^{-15}(\mathrm{ppq})$, and percentages.

but variations in the blank can severely limit the precision of the measurements at this level (see section 3.3). This is demonstrated by two exceptions to the generally low blank levels discussed below.

[9] The seaFAST system is supplied with two trace metal clean up columns in the uptake lines of the ammonium acetate buffer and the $\mathrm{H}_{2} \mathrm{O}$ carrier solutions. However, given that we only use the highest purity reagents we removed these columns to reduce the backpressure of the system and increase the lifetime of the peristaltic pump tubing. Interestingly, the removal of the trace metal clean up columns resulted in an increase of the Sm blank measured in both the $2 \% \mathrm{HNO}_{3}$ and $\mathrm{NaCl}$ matrix in $2 \% \mathrm{HNO}_{3}$ by a factor of 10 , for both ${ }^{147} \mathrm{Sm}$ and ${ }^{149} \mathrm{Sm}$. However, erroneous $\mathrm{Sm}$ concentrations, clearly evident in the REE patterns for the reference samples, were obtained using the high blank. We found using a blank value equivalent to that of $\mathrm{Nd}$ and $\mathrm{Eu}$ produced reliable results in these instances but the high blank was eventually eliminated by re-inserting the trace metal clean up column in the buffer line. Direct analysis of some buffer solution that was dried down and taken up in the equivalent volume of $2 \% \mathrm{HNO}_{3}$ shows the buffer contains detectable amounts of $\mathrm{Ce}, \mathrm{Pr}$ and $\mathrm{Sm}$, although it seems only the Sm measurements were adversely affected by the removal of the trace metal clean up column (section 3.3).

[10] With and without the trace metal clean up column in the buffer line, the blank of $\mathrm{Gd}$ in the $\mathrm{NaCl}$ matrix used to dilute the calibration standards was higher than in the $2 \% \mathrm{HNO}_{3}$ (Table 2). Therefore the $\mathrm{NaCl}$ matrix blank was applied to the calibration standards and the $2 \% \mathrm{HNO}_{3}$ blank was applied to the samples. This strategy resulted in reliable $\mathrm{Gd}$ concentrations but the reproducibility of the $\mathrm{Gd}$ measurements remained relatively poor (section 3.3) in part because of the lack of a single abundant isotope to measure. With the aim to improve the $\mathrm{Gd}$ measurements in the future we conducted experiments with REE free seawater obtained through co-precipitation of trace metals with $\mathrm{FeOOH}$ for $\mathrm{Nd}$ isotope analyses [e.g., Stichel et al., 2012]. These measurements confirm the higher Gd content of the $\mathrm{NaCl}$ matrix (Table 2), possibly related to the $\mathrm{NaCl}$ being sourced where Gd has been used for medical imaging [e.g., Bau and Dulski, 1996]. In the future we will try to use calibration standards made with this REE free seawater.

[11] No oxide corrections were applied as the oxide formation rate determined from the ${ }^{140} \mathrm{Ce} /{ }^{156} \mathrm{CeO}$ ratio while aspirating the tune solution was near $1 \%$. Tests with tune solution diluted with the elution acid showed a negligible increase in the oxide formation. Consequently, the oxides of the less abundant isotopes of the light REEs would represent less than $1 \%$ of the signal of the higher mass REEs that are enriched in seawater samples compared to continental rocks [Greaves et al., 1989].

\subsection{Column Yields and Removal of Matrix}

[12] Time resolved analysis demonstrates that the REEs are almost entirely eluted from the column within $60 \mathrm{~s}$ and, importantly, that the REEs do not fractionate when eluted from this resin (Figure 1). Using the uptake rate of $0.29 \mathrm{~mL} / \mathrm{min}$ for the $\mathrm{HNO}_{3}$ line (measured while eluting the column) the concentration factor for the REEs is around 15. The true volume of the sample loop $(4.19 \pm 0.08 \mathrm{~mL})$ was determined by filling it with Milli-Q water and then emptying this water into a pre-weighed plastic bottle to determine the mass. Column yields ranging from 94 to $102 \%$ (Table 2) were calculated by comparing standard TR peaks (Figure 1) with signals from standard solutions diluted with elution acid measured while bypassing the column. The yield experiments indicate no systematic bias in the retention and elution of the REEs. Initial yield experiments conducted with standard solutions diluted with $2 \% \mathrm{HNO}_{3}$ resulted in yields $10 \%$ too 
Table 3. Summary of Analyses of a Circumpolar Deep Water (CDW) Sample From $2000 \mathrm{~m}$ Water Depth in the Atlantic Sector of the Southern Ocean $\left(59^{\circ} \mathrm{N} / 0^{\circ} \mathrm{E}\right)$ Conducted Over 16 Analysis Days During 3 Months ${ }^{\mathrm{a}}$

\begin{tabular}{lccccccccccccccc}
\hline & $\mathrm{Y}^{*}$ & $\mathrm{La}$ & $\mathrm{Ce}$ & $\mathrm{Pr}$ & $\mathrm{Nd}$ & $\mathrm{Sm}$ & $\mathrm{Eu}$ & $\mathrm{Gd}$ & $\mathrm{Tb}$ & $\mathrm{Dy}$ & $\mathrm{Ho}$ & $\mathrm{Er}$ & $\mathrm{Tm}$ & $\mathrm{Yb}$ & $\mathrm{Lu}$ \\
\hline Average without buffer clean up column $(\mathrm{n}=32)$ & - & 40.9 & 5.5 & 6.0 & 25.7 & 4.9 & 1.2 & 6.8 & 1.1 & 7.8 & 2.1 & 7.1 & 1.1 & 7.6 & 1.4 \\
2 standard deviations & - & 2.4 & 0.5 & 0.8 & 2.4 & 1.2 & 0.2 & 0.8 & 0.1 & 0.8 & 0.2 & 0.7 & 0.1 & 1.0 & 0.1 \\
\% 2 sigma & - & 5.9 & 9.5 & 12.6 & 9.3 & 25.3 & 14.1 & 11.6 & 13.4 & 10.7 & 10.6 & 10.1 & 12.9 & 13.2 & 8.2 \\
Average with buffer clean up column $(\mathrm{n}=18)$ & 190.9 & 41.4 & 6.0 & 6.2 & 26.5 & 4.8 & 1.2 & 6.5 & 1.1 & 7.9 & 2.1 & 7.2 & 1.1 & 7.7 & 1.4 \\
2 standard deviations & 22.8 & 2.7 & 0.9 & 0.5 & 2.4 & 0.7 & 0.2 & 1.3 & 0.1 & 0.9 & 0.2 & 0.5 & 0.1 & 0.6 & 0.1 \\
\% 2 sigma & 12.0 & 6.6 & 15.4 & 7.7 & 8.9 & 13.8 & 16.9 & 20.3 & 13.4 & 11.0 & 8.5 & 7.6 & 11.0 & 7.9 & 7.2 \\
Average of all measurements ( $\mathrm{n}=50)$ & 190.9 & 41.1 & 5.6 & 6.1 & 26.0 & 4.9 & 1.2 & 6.7 & 1.1 & 7.8 & 2.1 & 7.1 & 1.1 & 7.6 & 1.4 \\
2 standard deviations & 22.8 & 2.6 & 0.8 & 0.7 & 2.5 & 1.1 & 0.2 & 1.0 & 0.2 & 0.8 & 0.2 & 0.7 & 0.1 & 0.9 & 0.1 \\
\% 2 sigma & 12.0 & 6.2 & 14.8 & 11.5 & 9.5 & 22.2 & 15.1 & 15.5 & 14.3 & 10.7 & 10.0 & 9.3 & 12.3 & 11.6 & 8.0 \\
5 point standard addition analysis & 184.2 & 41.1 & 6.2 & 6.0 & 26.0 & 5.0 & 1.1 & 7.0 & 1.1 & 7.7 & 2.1 & 7.1 & 1.0 & 7.6 & 1.5 \\
\hline
\end{tabular}

${ }^{a}$ Yttrium was only measured 11 times as it was only included in later measurement sessions. Units are pmol/kg except for the percentage 2 sigma.

high demonstrating the need for a consistent acid strength for both directly analyzed and eluted standards.

[13] The removal of matrix elements is highly efficient. The residual $\mathrm{Na}$ in the system injected with the column elution (Figure 1) is equivalent to between 50 and $250 \mathrm{ppb}$ and therefore the Na removal efficiency is $>99.999 \%$. Given that barium is known to interfere with REE analyses [e.g., Greaves et al., 1989], ${ }^{137} \mathrm{Ba}$ was monitored but was never found above blank levels in a wide variety of samples. The column capacity provided by the manufacturer is $20 \mu \mathrm{Eq}$ but as the resin clearly has little affinity for alkali and alkaline earth cations the most abundant cation in natural seawater competing for sites with the REEs is uranium. The $12.8 \mathrm{ng}$ of $\mathrm{U}$ in $4 \mathrm{~mL}$ of seawater would correspond to $<0.3 \mu \mathrm{Eq}$.

[14] A resin with IDA and ED3A functional groups, similar to that of the seaFAST column, has been shown to provide $\sim 100 \%$ recovery of the REEs and the efficient removal of the alkali and alkaline earth elements at $\mathrm{pH}$ values between 5 and 6 [Sohrin

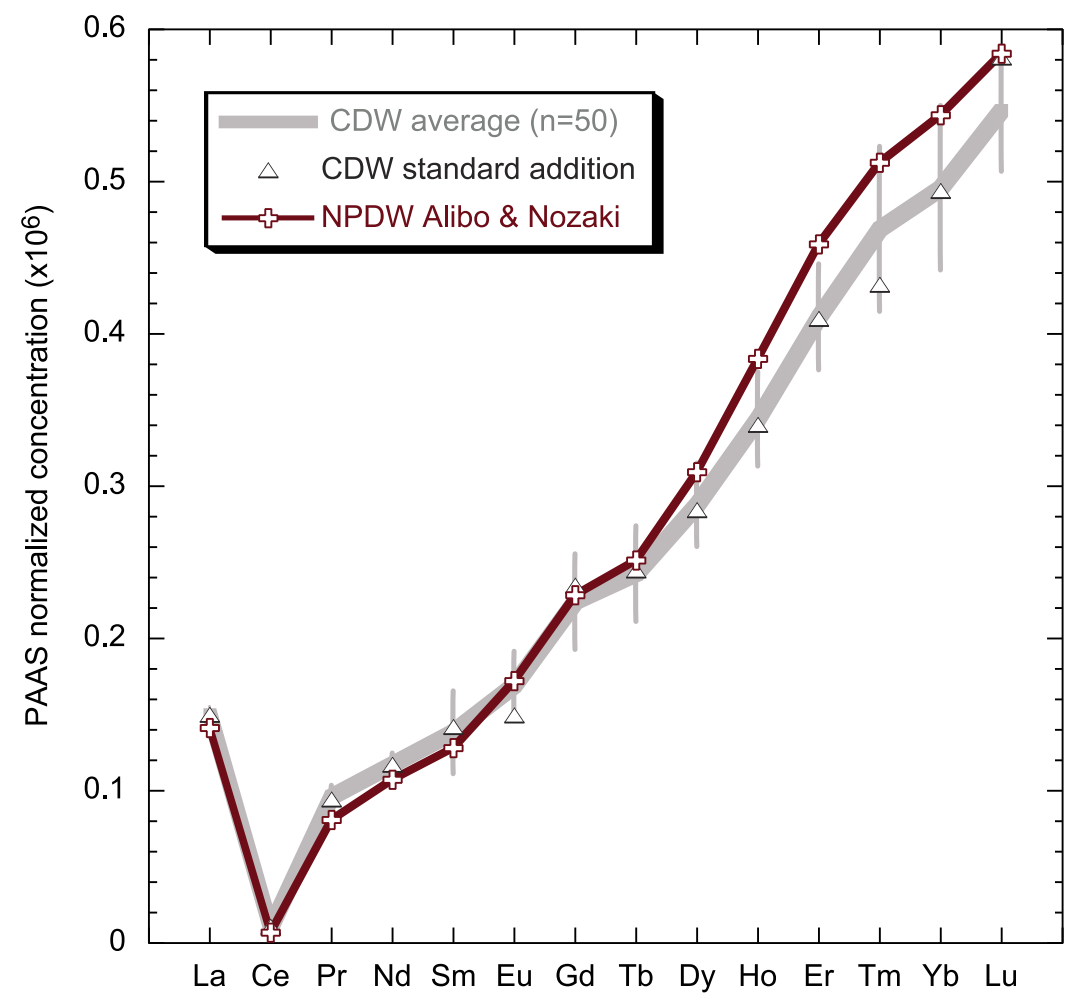

Figure 2. The PAAS normalized REE pattern of the CDW sample obtained from $2000 \mathrm{~m}$ water depth in the Atlantic sector of the Southern Ocean (Table 3). PAAS values are from Nance and Taylor [1976]. The North Pacific Deep Water (NPDW) REE pattern of Alibo and Nozaki [1999] is shown for comparison. 


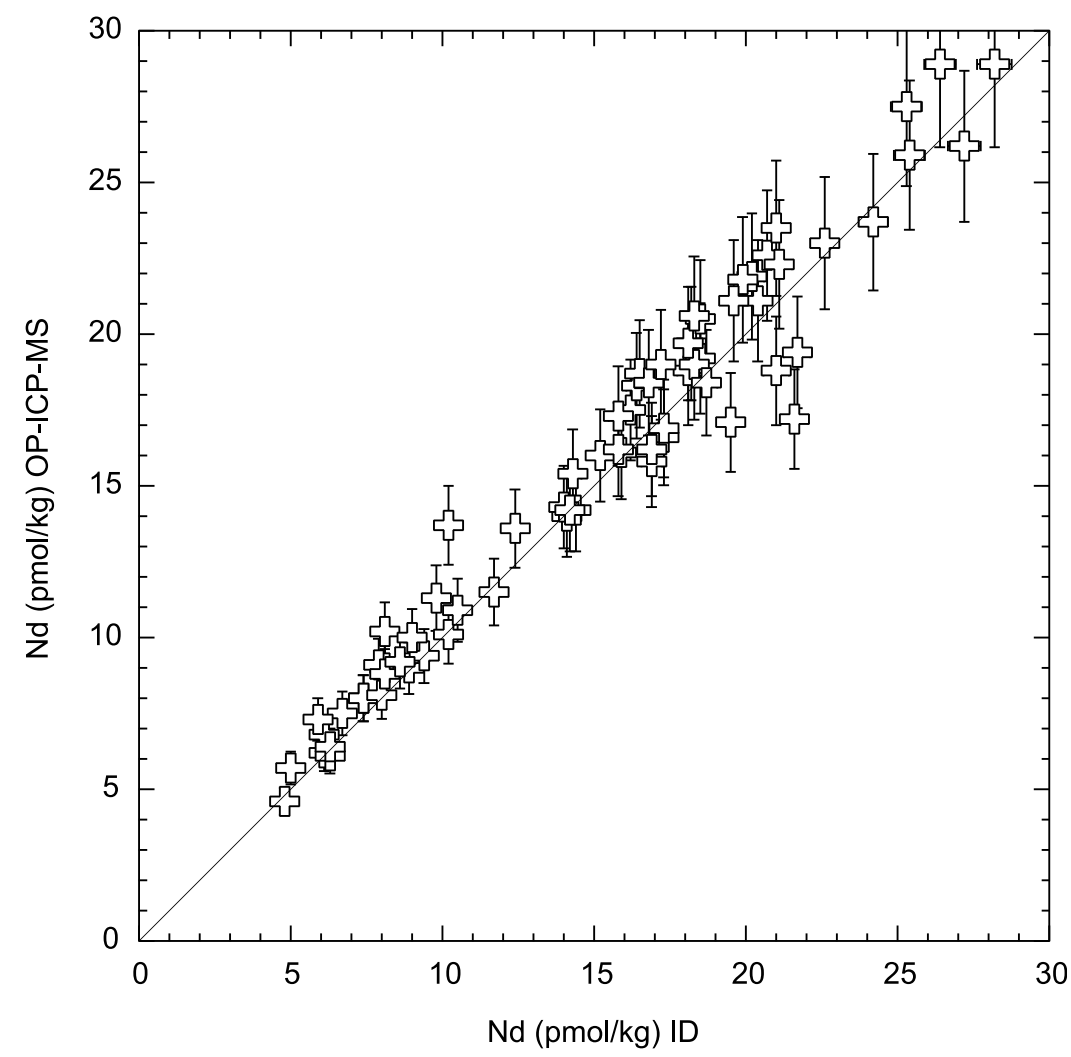

Figure 3. Comparison of Isotope Dilution (ID) MC-ICP-MS measurements of Nd concentrations in 69 seawater samples with the OP-ICP-MS derived Nd concentration for the same samples. Error bars represent the $2 \sigma$ external error (Table 3).

et al., 2008; Zhu et al., 2009, 2010]. Zhu et al. [2009, 2010] has used a resin with IDA and ED3A functional groups for manually operated OP-ICP-MS analysis of REEs in natural waters and a hybrid technique where pre-concentration and matrix removal are carried out offline before online elution using an automated column changing system. Our OP-ICP-MS technique is fully automated, commercially available, and has been successfully applied to the analysis of REEs in open ocean seawater [van de Flierdt et al., 2012]. Given the wide spread use of columns with IDA functional groups to preconcentrate metals such as $\mathrm{Mn}, \mathrm{Ni}$, $\mathrm{Co}, \mathrm{Cu}, \mathrm{Zn}, \mathrm{Cd}, \mathrm{Pb}$, and $\mathrm{U}$ in seawater samples [e.g., McLaren et al., 1993; Ebdon et al., 1993; Taylor et al., 1996] this OP-ICP-MS technique is likely to work for other trace metals.

\subsection{Reproducibility and Accuracy}

[15] Repeated measurement $(n=50)$ of a sample of Circumpolar Deep Water (CDW) recovered from $2000 \mathrm{~m}$ water depth in the Atlantic sector of the Southern Ocean during different analytical sessions within a 3 month period, reveals the external reproducibility of the technique at the $95 \%$ confidence level $(2 \sigma)$ to be between 6 and $22 \%$ (Table 3). Generally, the best precision is obtained for the more abundant light REEs (La) but the precision for the sub ppt level heavy REEs is also around $10 \%$. This compares favorably with other ICP-MS techniques determining REEs in natural waters [e.g., Shabani et al., 1990; Hall et al., 1995; Halicz et al., 1996; Willie and Sturgeon, 2001; Hirata et al., 2002; Kajiya et al., 2004; Fu et al., 2007; Zhu et al., 2009], in particular considering the small sample volume analyzed. The poorer reproducibility of Sm measurements was clearly related to the relatively high background counts that have been eliminated with the trace metal cleanup column in the buffer line (section 3.1). The reproducibility for $\mathrm{Eu}, \mathrm{Gd}$, and $\mathrm{Tb}$ is only slightly worse than average (Table 3), a good result considering the difficulties experienced during the measurement of these elements in complex matrices during inter-laboratory studies [Verplanck et al., 2001; Santos et al., 2008]. 


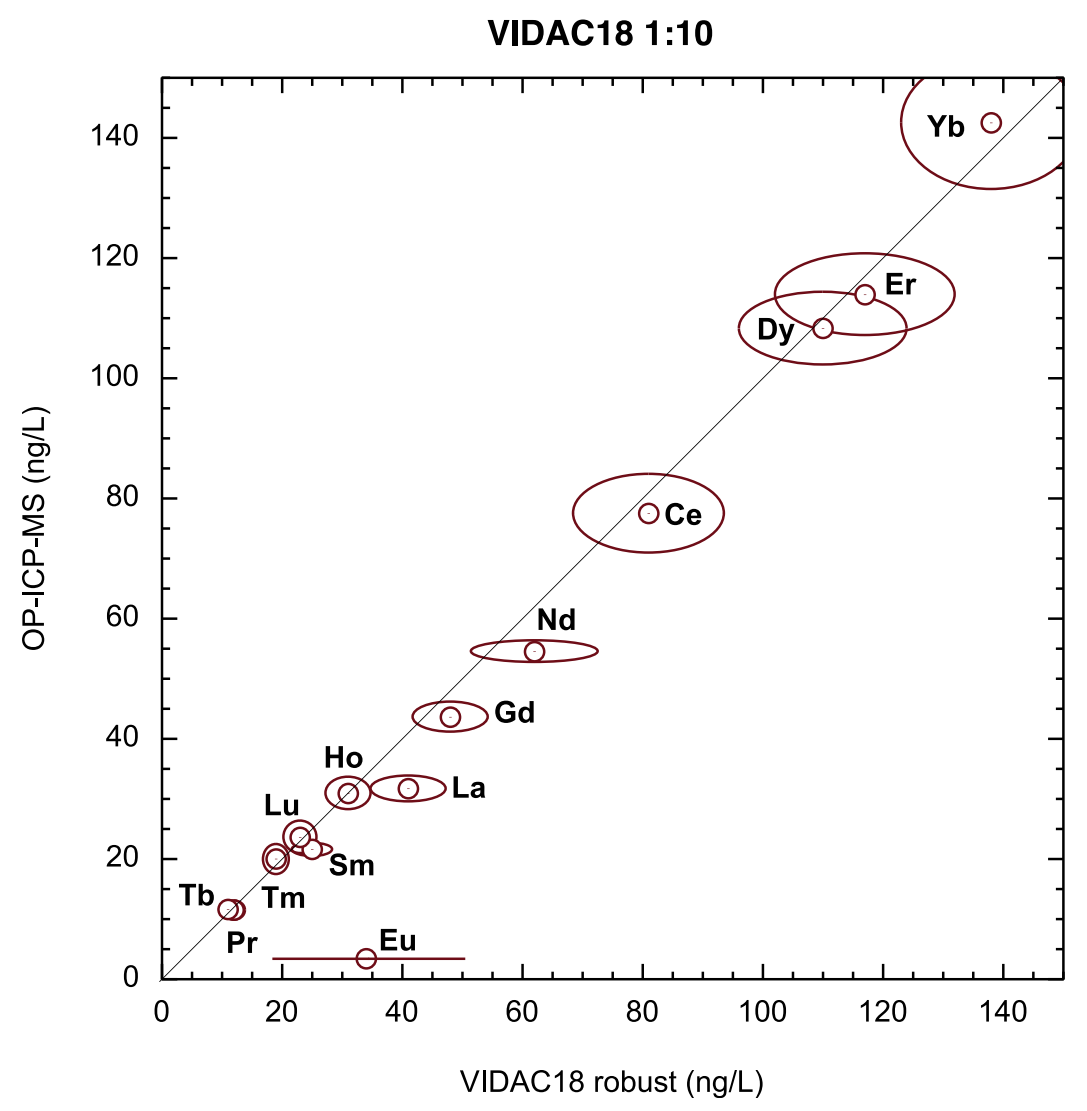

Figure 4. Comparison of OP-ICP-MS measurements of the VIDAC18 reference mine water with the "robust" values of Santos et al. [2008]. The VIDAC18 was diluted by a factor of ten before OP-ICP-MS analysis and the error ellipse represents the standard deviation of two measurements for OP-ICP-MS and the $99 \%$ confidence interval for the literature values.

[16] To assess the accuracy of the technique we have employed three different approaches. The first approach was to conduct standard additions to the CDW seawater sample. The CDW sample was passed through the column with different additions of standard in the same way as normal samples. Figure 2 shows the excellent agreement of the results of the standard addition analysis of the CDW sample with the average results obtained from the repeated regular measurements (Table 3 ). The shale normalized pattern for NPDW [Alibo and Nozaki, 1999] is also shown and is almost indistinguishable from that of the CDW sample. This is a noteworthy result considering the different preconcentration techniques used.

[17] Isotope dilution offers the most precise way to determine the concentration of REEs in seawater and we have analyzed a suite of 69 seawater samples, for which the $\mathrm{Nd}$ concentration was previously measured by isotope dilution MC-ICP-MS [Stichel et al., 2012]. The comparison of the isotope dilution $\mathrm{Nd}$ concentrations with those determined by the OP-ICP-MS technique (Figure 3) shows very good agreement, within $15 \%$ for all but 4 samples. This is close to the estimated external reproducibility of the OP-ICP-MS technique (Table 3).

[18] The final method we have used to assess the accuracy of the technique is by measuring reference samples, for which values have been reported in the literature. Given that there are currently no suitable reference seawater samples for the REEs (NASS-5 has a salinity of only 30.4 per mil, is not certified for the REEs and seems to be contaminated with Sm [Lawrence and Kamber, 2007]), we have measured mine wastewater reference materials diluted with a $\mathrm{NaCl}$ matrix. Comparison of the data obtained by the online pre-concentration technique for the 1:10 dilution of VIDAC18 and published data show agreement within uncertainties for all REE except $\mathrm{La}$ and $\mathrm{Eu}$ (Figure 4). However, Santos et al. [2008] did not provide recommended values for $\mathrm{La}$ and $\mathrm{Eu}$ because of poor agreement between labs. The USGS has produced REE reference acid mine waters called SCREE and PPREE [Verplanck et al., 2001], but the high concentrations of REEs in these 

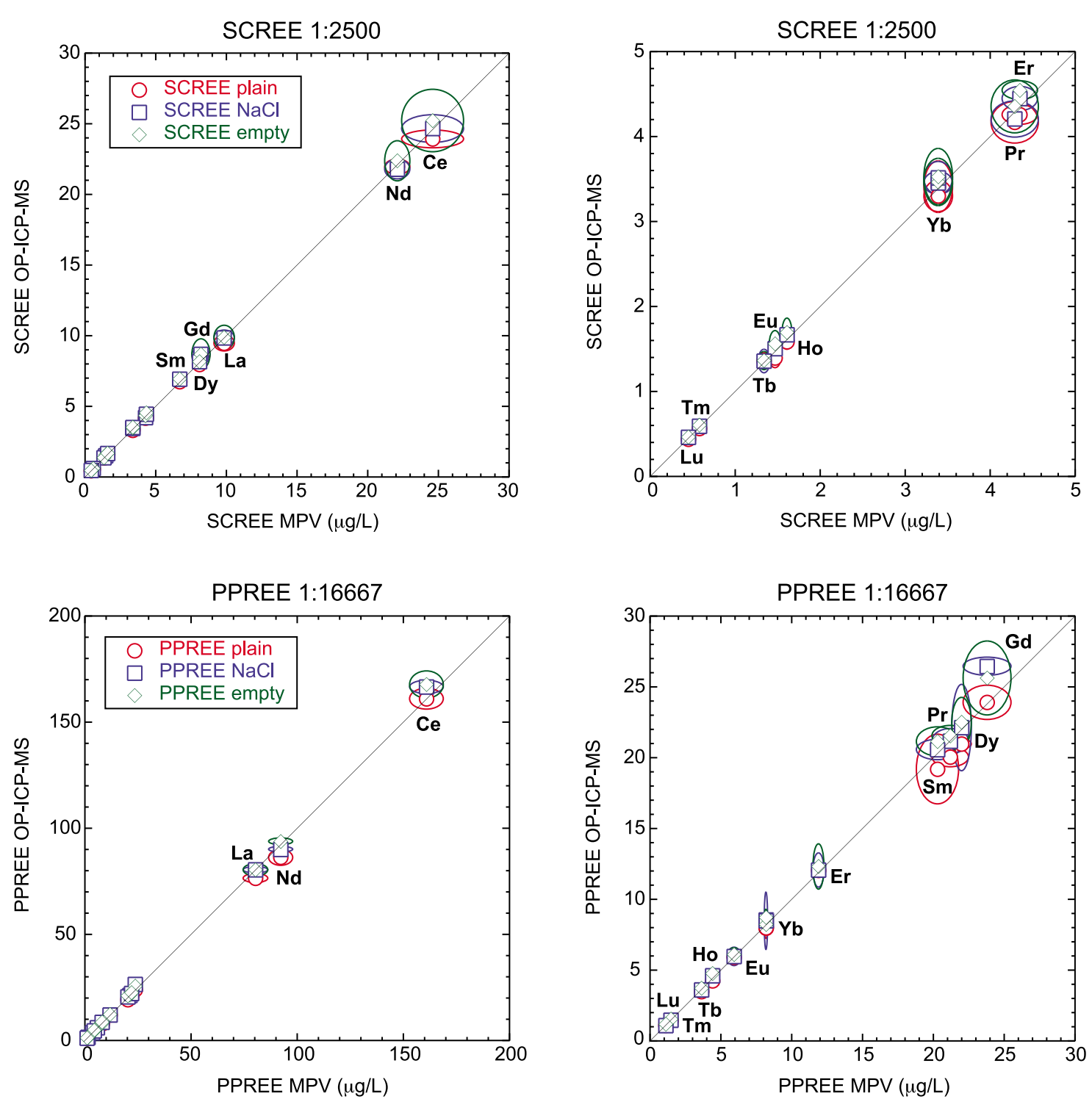

Figure 5. Comparison of Most Probable Values (MPV) for USGS mine water reference materials [Verplanck et al., 2001] with those measured by OP-ICP-MS on dilutions made with a plain $2 \% \mathrm{HNO}_{3}$ matrix (plain), a $35 \mathrm{~g} / \mathrm{L} \mathrm{NaCl}$ matrix in $2 \% \mathrm{HNO}_{3}(\mathrm{NaCl})$, and seawater remaining after trace metals have been co-precipitated with $\mathrm{Fe}$ hydroxides (empty). Error ellipses represent the standard deviation of 3 repeat measurements $(2 \sigma)$ for OP-ICP-MS and the MAD from Verplanck et al. [2001]. Normalization to account for evaporation during storage was conducted using La measured in the $\mathrm{NaCl}$ matrix and amounted to $30 \%$ for SCREE and $15 \%$ for PPREE.

waters required large dilutions to reach the appropriate REE abundances for our study. To investigate the effect of residual matrix and the different natural and artificial matrices, we diluted the SCREE and PPREE solutions in 3 ways (Figure 5). First, only $2 \% \mathrm{HNO}_{3}$ was used to dilute, second the artificial $\mathrm{NaCl}$ in $2 \% \mathrm{HNO}_{3}$ was used and finally the natural seawater remaining after the REEs and other trace metals have been co-precipitated with Fe hydroxides, acidified to $2 \% \mathrm{HNO}_{3}$, was used. Although the SCREE and PPREE solutions diluted with only $2 \% \mathrm{HNO}_{3}$ tend to exhibit lower values than those from salty matrices, all matrices agree within uncertainty for all REEs except $\mathrm{Gd}$. The $\mathrm{NaCl}$ matrix is contaminated with Gd (Table 2).

\subsection{Application: Profiles From the Atlantic Sector of the Southern Ocean}

[19] In order to demonstrate the applicability of the OP-ICP-MS technique we have analyzed two depth profiles from the Atlantic sector of the Southern Ocean collected during the GEOTRACES expedition ANTXXIV/3 on R/V Polarstern (Station 178, 

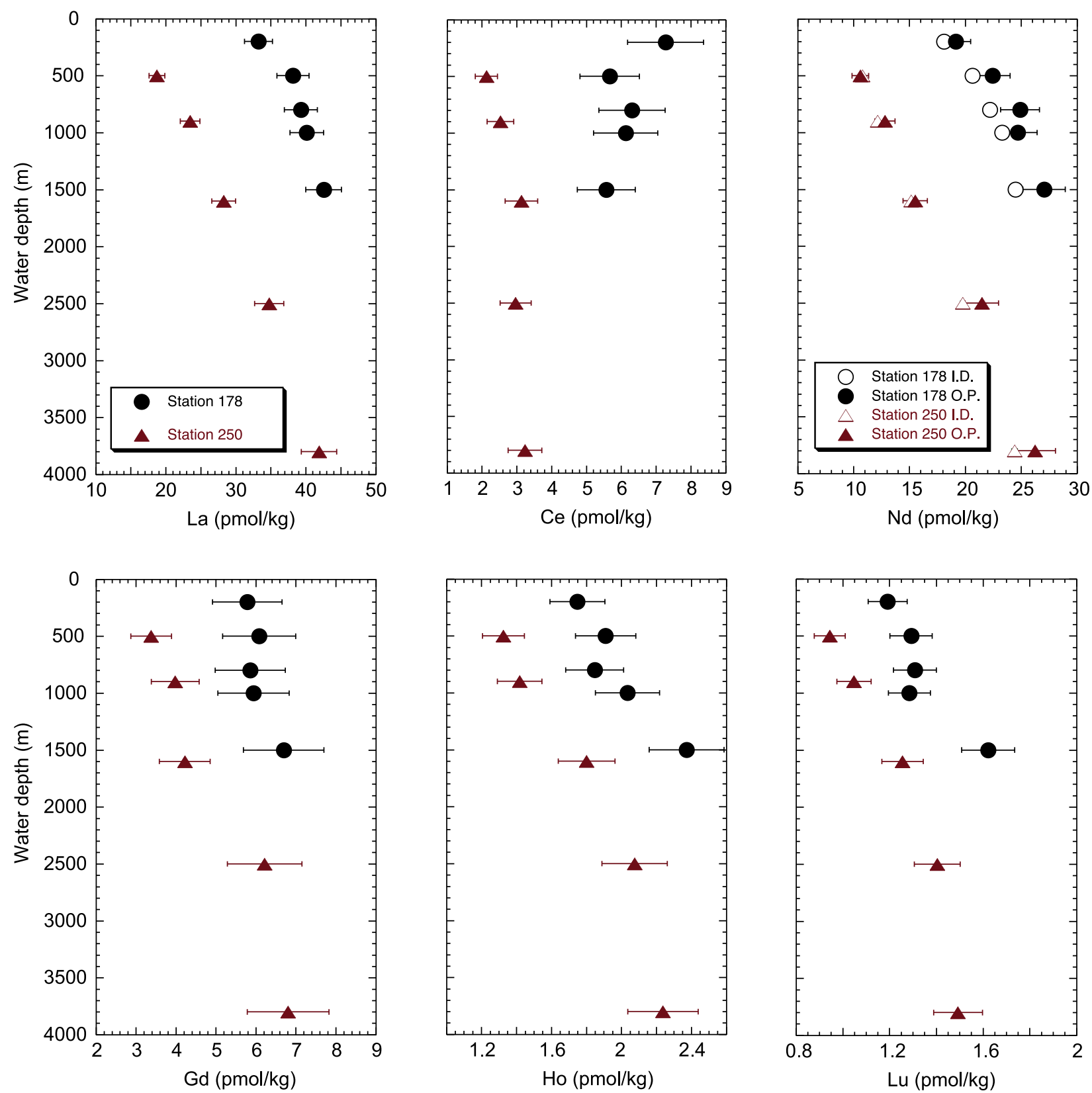

Figure 6. Southern Ocean water column profiles for selected REEs measured with the OP-ICP-MS technique. The isotope dilution derived Nd concentrations of Stichel et al. [2012] are shown for comparison. Error bars represent the $2 \sigma$ external error (Table 3 ).

water depth $2000 \mathrm{~m}, 6^{\circ} 23^{\prime} \mathrm{S} / 0^{\circ} \mathrm{E}$; Station 250 , water depth $\left.3800 \mathrm{~m}, 55^{\circ} 45^{\prime} \mathrm{S}, 64^{\circ} 26^{\prime} \mathrm{W}\right)$. Comparison with the ID results shows that the OP technique agrees within uncertainty ( $2 \sigma$ is $9.5 \%$ ) for all but one sample. Station 178, located above the continental slope of Antarctica, has higher REE levels than station 250 and the difference is largest for the LREE compared to the HREE. A full interpretation of these data will require more profiles and is beyond the scope of this contribution. However, these data demonstrate the ability of the OP-ICP-MS technique to generate oceanographically consistent data for truly open ocean samples. The fact that the data in Figure 6 took $<3 \mathrm{~h}$ to collect, including about $15 \mathrm{~min}$ of operator time, clearly testifies to the power of the OP-ICP-MS technique.

\section{Conclusions}

[20] Overall, the online preconcentration technique provides a precise and accurate way to measure 
REEs in seawater samples quickly with minimal sample preparation and small sample size. The external precision of the technique at the $95 \%$ confidence level is estimated to be $<23 \%$ for all REEs and $<15 \%$ for most which compares favorably considering the small volume of sample consumed $(7 \mathrm{~mL})$ per analysis. The OP-ICP-MS technique clearly produces reliable data for truly open ocean seawater samples and will enable high density sampling campaigns such as desired for GEOTRACES to be conducted for the REEs in seawater. The system used is commercially available meaning this technique can be readily adopted by other laboratories and the global data set of REEs in seawater can be greatly improved.

\section{Acknowledgments}

[21] The helpful comments of Germain Bayon and one anonymous reviewer are gratefully acknowledged. We thank Jutta Heinze for all the clean tubes and Anton Eisenhauer and Ana Kolevica for the use of the mass spectrometer.

\section{References}

Aggarwal, J. K., M. B. Shabani, M. R. Palmer, and K. V. Ragnarsdottir (1996), Determination of the rare earth elements in aqueous samples at sub-ppt levels by inductively coupled plasma mass spectrometry and flow injection ICPMS, Anal. Chem., 68(24), 4418-4423, doi:10.1021/ac9602074.

Alibo, D. S., and Y. Nozaki (1999), Rare earth elements in seawater: Particle association, shale-normalization, and $\mathrm{Ce}$ oxidation, Geochim. Cosmochim. Acta, 63(3-4), 363-372, doi:10.1016/S0016-7037(98)00279-8.

Amakawa, H., D. S. Alibo, and Y. Nozaki (2000), Nd isotopic composition and REE pattern in the surface waters of the eastern Indian Ocean and its adjacent seas, Geochim. Cosmochim. Acta, 64(10), 1715-1727, doi:10.1016/S0016-7037(00)00333-1.

Bau, M., and P. Dulski (1996), Anthropogenic origin of positive gadolinium anomalies in river waters, Earth Planet. Sci. Lett., 143, 245-255, doi:10.1016/0012-821X(96)00127-6.

Bayon, G., D. Birot, C. Bollinger, and J. A. Barrat (2011), Multi-element determination of trace elements in natural water reference materials by ICP-SFMS after Tm addition and iron co-precipitation, Geostand. Geoanal. Res., 35(1), 145-153, doi:10.1111/j.1751-908X.2010.00064.x.

Bertram, C. J., and H. Elderfield (1993), The geochemical balance of the rare earth elements and neodymium isotopes in the oceans, Geochim. Cosmochim. Acta, 57(9), 1957-1986, doi:10.1016/0016-7037(93)90087-D.

Cantrell, K. J., and R. H. Byrne (1987), Rare earth element complexation by carbonate and oxalate ions, Geochim. Cosmochim. Acta, 51(3), 597-605, doi:10.1016/0016-7037(87) 90072-X.

Censi, P., S. Mazzola, M. Sprovieri, A. Bonanno, B. Patti, R. Punturo, S. E. Spoto, F. Saiano, and G. Alonzo (2004), Rare earth elements distribution in seawater and suspended particulate of the Central Mediterranean Sea, Chem. Ecol., 20(5), 323-343, doi:10.1080/02757540410001727954.
De Baar, H. J. W., M. P. Bacon, P. G. Brewer, and K. W. Bruland (1985), Rare earth elements in the Pacific and Atlantic Oceans, Geochim. Cosmochim. Acta, 49(9), 1943-1959, doi:10.1016/0016-7037(85)90089-4.

Douville, E., J. L. Charlou, E. H. Oelkers, P. Bienvenu, C. F. Jove Colon, J. P. Donval, Y. Fouquet, D. Prieur, and P. Appriou (2002), The rainbow vent fluids $\left(36^{\circ} 14^{\prime} \mathrm{N}\right.$, MAR): The influence of ultramafic rocks and phase separation on trace metal content in Mid-Atlantic Ridge hydrothermal fluids, Chem. Geol., 184(1-2), 37-48, doi:10.1016/ S0009-2541(01)00351-5.

Ebdon, L., A. Fisher, H. Handley, and P. Jones (1993), Determination of trace metals in concentrated brines using inductively coupled plasma mass spectrometry on-line preconcentration and matrix elimination with flow injection, J. Anal. At. Spectrom., 8(7), 979-981, doi:10.1039/ja9930800979.

Elderfield, H. (1988), The oceanic chemistry of the rare-earth elements, [and Discussion], Philos. Trans. R. Soc. London, Ser. A, 325(1583), 105-126, doi:10.1098/rsta.1988.0046.

Elderfield, H., and M. J. Greaves (1982), The rare earth elements in seawater, Nature, 296(5854), 214-219, doi:10.1038/ $296214 \mathrm{a} 0$.

Freslon, N., G. Bayon, D. Birot, C. Bollinger, and J. A. Barrat (2011), Determination of rare earth elements and other trace elements ( $\mathrm{Y}, \mathrm{Mn}, \mathrm{Co}, \mathrm{Cr}$ ) in seawater using Tm addition and $\mathrm{Mg}(\mathrm{OH})_{2}$ co-precipitation, Talanta, 85(1), 582-587, doi:10.1016/j.talanta.2011.04.023.

Fu, Q., L. Yang, and Q. Wang (2007), On-line preconcentration with a novel alkyl phosphinic acid extraction resin coupled with inductively coupled plasma mass spectrometry for determination of trace rare earth elements in seawater, Talanta, 72(4), 1248-1254, doi:10.1016/j.talanta.2007.01.015.

German, C. R., and H. Elderfield (1990a), Rare earth elements in the NW Indian Ocean, Geochim. Cosmochim. Acta, 54(7), 1929-1940, doi:10.1016/0016-7037(90)90262-J.

German, C. R., and H. Elderfield (1990b), Application of the $\mathrm{Ce}$ anomaly as a paleoredox indicator: The ground rules, Paleoceanography, 5, 823-833, doi:10.1029/PA005i005p00823.

Greaves, M. J., H. Elderfield, and G. P. Klinkhammer (1989), Determination of the rare earth elements in natural waters by isotope-dilution mass spectrometry, Anal. Chim. Acta, 218, 265-280, doi:10.1016/S0003-2670(00)80303-7.

Haley, B. A., and G. P. Klinkhammer (2003), Complete separation of rare earth elements from small volume seawater samples by automated ion chromatography: Method development and application to benthic flux, Mar. Chem., 82(3-4), 197-220, doi:10.1016/S0304-4203(03)00070-7.

Halicz, L., I. Gavrieli, and E. Dorfman (1996), On-line method for inductively coupled plasma mass spectrometric determination of rare earth elements in highly saline brines, J. Anal. At. Spectrom., 11(9), 811-814, doi:10.1039/ja9961100811.

Hall, G. E. M., J. E. Vaive, and J. W. McConnell (1995), Development and application of a sensitive and rapid analytical method to determine the rare-earth elements in surface waters, Chem. Geol., 120(1-2), 91-109, doi:10.1016/00092541(94)00110-T.

Hirata, S., T. Kajiya, M. Aihara, K. Honda, and O. Shikino (2002), Determination of rare earth elements in seawater by on-line column preconcentration inductively coupled plasma mass spectrometry, Talanta, 58(6), 1185-1194, doi:10.1016/ S0039-9140(02)00418-6.

Kajiya, T., M. Aihara, and S. Hirata (2004), Determination of rare earth elements in seawater by inductively coupled plasma mass spectrometry with on-line column pre-concentration using 8-quinolinole-immobilized fluorinated metal alkoxide 
glass, Spectrochimica Acta Part B, 59(4), 543-550, doi:10.1016/j. sab.2003.12.019.

Kim, I., S. Kim, and G. Kim (2010), Analytical artefacts associated with the chelating resin extraction of dissolved rare earth elements in natural water samples, Aquat. Geochem., 16(4), 611-620, doi:10.1007/s10498-010-9100-5.

Kulaksiz, S., and M. Bau (2011), Rare earth elements in the Rhine River, Germany: First case of anthropogenic lanthanum as a dissolved microcontaminant in the hydrosphere, Environ. Int., 37, 973-979, doi:10.1016/j.envint.2011.02.018.

Lawrence, M. G., and B. S. Kamber (2007), Rare earth element concentrations in the Natural Water Reference Materials (NRCC) NASS-5, CASS-4 and SLEW-3, Geostand. Geoanal. Res., 31(2), 95-103, doi:10.1111/j.1751-908X.2007.00850.x.

McLaren, J. W., J. W. H. Lam, S. S. Berman, K. Akatsuka, and M. A. Azeredo (1993), On-line method for the analysis of sea-water for trace elements by inductively coupled plasma mass spectrometry. Plenary lecture, J. Anal. At. Spectrom., 8(2), 279-286, doi:10.1039/ja9930800279.

Möller, P., P. Dulski, and J. Luck (1992), Determination of rare earth elements in seawater by inductively coupled plasmamass spectrometry, Spectrochimica Acta Part B, 47(12), 1379-1387, doi:10.1016/0584-8547(92)80128-4.

Nance, W. B., and S. R. Taylor (1976), Rare earth element patterns and crustal evolution-I. Australian post-Archean sedimentary rocks, Geochim. Cosmochim. Acta, 40(12), 1539-1551, doi:10.1016/0016-7037(76)90093-4.

Nozaki, Y., and D. S. Alibo (2003), Importance of vertical geochemical processes in controlling the oceanic profiles of dissolved rare earth elements in the northeastern Indian Ocean, Earth Planet. Sci. Lett., 205(3-4), 155-172, doi:10.1016/S0012-821X(02)01027-0.

Nozaki, Y., D.-S. Alibo, H. Amakawa, T. Gamo, and H. Hasumoto (1999), Dissolved rare earth elements and hydrography in the Sulu Sea, Geochim. Cosmochim. Acta, 63(15), 2171-2181, doi:10.1016/S0016-7037(99)00142-8.

Piepgras, D. J., and S. B. Jacobsen (1992), The behavior of rare earth elements in seawater: Precise determination of variations in the North Pacific water column, Geochim. Cosmochim. Acta, 56(5), 1851-1862, doi:10.1016/0016-7037(92) 90315-A.

Quinn, K. A., R. H. Byrne, and J. Schijf (2006), Sorption of yttrium and rare earth elements by amorphous ferric hydroxide: Influence of solution complexation with carbonate, Geochim. Cosmochim. Acta, 70(16), 4151-4165, doi:10.1016/j.gca. 2006.06.014.

Rahmi, D., Y. Zhu, E. Fujimori, T. Umemura, and H. Haraguchi (2007), Multielement determination of trace metals in seawater by ICP-MS with aid of down-sized chelating resin-packed minicolumn for preconcentration, Talanta, 72(2), 600-606, doi:10.1016/j.talanta.2006.11.023.

Santos, R., M. J. C. Machado, and L. Cortez (2008), SERMIN1 and VIDAC18: Two proposed reference materials for rare earth element determination in groundwater, Geostand. Geoanal. Res., 32(2), 181-191, doi:10.1111/j.1751-908X.2008.00878.x.

Shabani, M. B., and A. Masuda (1991), Sample introduction by on-line two-stage solvent extraction and back-extraction to eliminate matrix interference and to enhance sensitivity in the determination of rare earth elements with inductively coupled plasma mass spectrometry, Anal. Chem., 63(19), 2099-2105, doi:10.1021/ac00019a007.

Shabani, M. B., T. Akagi, H. Shimizu, and A. Masuda (1990), Determination of trace lanthanides and yttrium in seawater by inductively coupled plasma mass spectrometry after preconcentration with solvent extraction and back-extraction, Anal. Chem., 62(24), 2709-2714, doi:10.1021/ac00223a012.

Shaw, T. J., T. Duncan, and B. Schnetger (2003), A preconcentration/matrix reduction method for the analysis of rare earth elements in seawater and groundwaters by isotope dilution ICPMS, Anal. Chem., 75(14), 3396-3403, doi:10.1021/ ac026158e

Sholkovitz, E. R., and D. L. Schneider (1991), Cerium redox cycles and rare earth elements in the Sargasso Sea, Geochim. Cosmochim. Acta, 55(10), 2737-2743, doi:10.1016/00167037(91)90440-G.

Sholkovitz, E. R., W. M. Landing, and B. L. Lewis (1994), Ocean particle chemistry: The fractionation of rare earth elements between suspended particles and seawater, Geochim. Cosmochim. Acta, 58(6), 1567-1579, doi:10.1016/00167037(94)90559-2.

Sohrin, Y., S. Urushihara, S. Nakatsuka, T. Kono, E. Higo, T. Minami, K. Norisuye, and S. Umetani (2008), Multielemental determination of GEOTRACES key trace metals in seawater by ICPMS after preconcentration using an ethylenediaminetriacetic acid chelating resin, Anal. Chem., 80(16), 6267-6273, doi:10.1021/ac800500f.

Stichel, T., M. Frank, J. Rickli, and B. Haley (2012), The hafnium and neodymium isotope composition of the Atlantic sector of the Southern Ocean, Earth Planet. Sci. Lett., 317-318, 282-294.

Taylor, D. B., H. M. Kingston, D. J. Nogay, D. Koller, and R. Hutton (1996), On-line solid-phase chelation for the determination of eight metals in environmental waters by inductively coupled plasma mass spectrometry, J. Anal. At. Spectrom., 11(3), 187-191, doi:10.1039/ja9961100187.

van de Flierdt, T., K. Pahnke, and the GEOTRACES Intercalibration Participants (2012), GEOTRACES intercalibration of neodymium isotopes and rare earth elements in seawater and marine particulates-Part 1: International intercomparison, Limnol. Oceanogr. Methods, in press.

Verplanck, P. L., R. C. Antweiler, D. K. Nordstrom, and H. E. Taylor (2001), Standard reference water samples for rare earth element determinations, Appl. Geochem., 16(2), 231-244, doi:10.1016/S0883-2927(00)00030-5.

Willie, S. N., and R. E. Sturgeon (2001), Determination of transition and rare earth elements in seawater by flow injection inductively coupled plasma time-of-flight mass spectrometry, Spectrochimica Acta Part B, 56(9), 1707-1716, doi:10.1016/ S0584-8547(01)00263-4.

Zhang, J., and Y. Nozaki (1996), Rare earth elements and yttrium in seawater: ICP-MS determinations in the East Caroline, Coral Sea, and South Fiji basins of the western South Pacific Ocean, Geochim. Cosmochim. Acta, 60(23), 4631-4644, doi:10.1016/S0016-7037(96)00276-1.

Zhu, Y., A. Itoh, E. Fujimori, T. Umemura, and H. Haraguchi (2006), Determination of rare earth elements in seawater by ICPMS after preconcentration with a chelating resin-packed minicolumn, J. Alloys Compd., 408-412, 985-988, doi:10.1016/j. jallcom.2004.12.092.

Zhu, Y., T. Umemura, H. Haraguchi, K. Inagaki, and K. Chiba (2009), Determination of REEs in seawater by ICP-MS after on-line preconcentration using a syringe-driven chelating column, Talanta, 78(3), 891-895, doi:10.1016/j.talanta.2008.12.072.

Zhu, Y., A. Itoh, T. Umemura, H. Haraguchi, K. Inagaki, and K. Chiba (2010), Determination of REEs in natural water by ICP-MS with the aid of an automatic column changing system, J. Anal. At. Spectrom., 25(8), 1253-1258, doi:10.1039/ c003125a. 